\title{
Effect of Stabilization Conditions on the Fabrication of Carbon Membranes for $\mathrm{CO}_{2}$ Separation
}

\author{
W. N. W. Salleh ${ }^{1,2}$, A. F. Ismail ${ }^{1,2^{*}} \&$ M. A. Rahman ${ }^{1,2}$ \\ ${ }^{1}$ Advanced Membrane Technology Research Centre, Universiti Teknologi Malaysia, 81310 Skudai, Johor Bahru, \\ Malaysia \\ ${ }^{2}$ Faculty of Petroleum and Renewable Energy Engineering, Universiti Teknologi Malaysia, 81310 Skudai, Johor \\ Bahru, Malaysia
}

\begin{abstract}
Preparation of carbon membranes has rapidly attracted much attention in gas separation processes because of thermal and chemical stabilities and exhibit superior separation performance. Carbon hollow fiber membranes (CHFM)s derived from polymer blend of polyetherimide (PEI) and polyvinylpyrrolidone (PVP) were extensively prepared through stabilization under air atmosphere followed by carbonization under $\mathrm{N}_{2}$ atmosphere. The effects of the stabilization temperature on the morphological structure and gas permeation properties were investigated by means of scanning electron microscopy (SEM) and single gas permeation system. Experimental results indicate that the transport mechanism of small gas molecules of $\mathrm{N}_{2}, \mathrm{CO}_{2}$, and $\mathrm{CH}_{4}$ is dominated by the molecular sieving effect. Based on morphological structure and gas permeation properties, an optimum stabilization condition for the preparation of CHFM derived from PEI/PVP was found at $300^{\circ} \mathrm{C}$ under air atmosphere. The selectivity of about 55 and 41 for $\mathrm{CO}_{2} / \mathrm{CH}_{4}$ and $\mathrm{CO}_{2} / \mathrm{N}_{2}$, respectively, were obtained.
\end{abstract}

Keyword: Carbon membrane, hollow fiber, gas separation, stabilization, carbon dioxide

\subsection{INTRODUCTION}

In 1980s, the developments in the field of gas separation by membranes were accelerated by the developments of synthetic polymeric membrane and became a commercial process on a large scale. During this period, significant progress were made in every aspect of membranology, including improvements in formation of membrane, chemical and physical structures, configurations, and applications [1]. Nevertheless, the utilization of polymeric membrane in rigorous environment has been restricted by their poor chemical and thermal resistance. The shortcomings of polymeric membranes have motivated the researchers to study other alternative materials for membrane separation in order to defeat the

* Corresponding to: A. F. Ismail (email: afauzi@utm.my) present challenges and competition in current separation technologies. Carbon membranes with excellent thermal and chemical resistances have come into the contest, where it exhibit high separation performance compared to their polymeric precursor membranes [2, 3]. Although significant research works have been made since carbon membranes inception, there remains the need to significantly improve the permeation properties of these membranes if they are to become viable for real applications. Numerous studies have been reported on the effect of process parameters on the gas permeation properties of the polymer-based carbon membranes [4-7].

In this study, carbon membrane derived from polymer blend of polyetherimide (PEI)/ polyvinylpyrrolidone (PVP) in self supporting form for $\mathrm{CO}_{2}$ separation were prepared. The PEI polymer is a kind of thermoplastic polymer, which 
would go through a melting or softening stage during carbonization step. However, the melting stage is unfavorable for the preparation of the carbon membranes. It is because the microporous structure evolved would be destroying due to the removal of functional groups in the form of volatiles or gases during carbonization. As a result, stabilization step prior to carbonization is recommended to prevent thermoplastic polymers from melting stage at high temperatures and helps to maintain the morphology and structure of the precursor in the resultant carbon membranes [8, 9]. Until now, the detailed studies on the effect of the stabilization conditions in the PEI/PVP-based carbon hollow fiber membranes fabrication have not yet reported in the literature. Thus, the design of PEI/ PVP-based carbon hollow fiber membranes is engineered to study the properties of the resultant carbon membranes as well as their permeance and selectivity by manipulating the stabilization temperatures.

\subsection{RESEARCH METHODOLOGY}

\subsection{Carbon Hollow Fiber Membrane Preparation and Characterization}

In this paper, PEI (Ultem 1000) as the basic polymer and PVP (Fluka, K90) as the second polymer were used for making the blend membrane. Both polymers were dried overnight at $120^{\circ} \mathrm{C}$ prior use to remove any absorbed water. The chemical N-methyl-2-pyrrolidone (NMP) with analytical grade was used as solvent without any purification. Polymeric hollow fiber membranes with $17 \mathrm{wt} \% \mathrm{PEI} / 6 \mathrm{wt} \%$ PVP was used as a precursor membranes. This formulation was adapted from previous studies performed by Coutinho and coworkers in 2003 [5]. These membranes were fabricated using dry/wet spinning process. The details on the experimental procedures included heat treatment profile and spinning condition used in this study can be found elsewhere $[10,11]$. Morphological structure images were obtained in a JEOL JSM-5610LV scanning electron microscopy (SEM).

\subsection{Carbon Hollow Fiber Membrane Performance Measurement}

The membrane performances were measured by two important parameters: permeance and selectivity. These parameters were examined using a single gas permeation system $[12,13]$. The permeance, $P$ (GPU) and selectivity, $\alpha$ of the membranes were calculated using the following equations:

Permeance, $P$ (GPU):

$$
\begin{aligned}
& \left(\frac{P}{l}\right)_{i}=\frac{Q_{i}}{\Delta p \cdot A}=\frac{Q}{n \pi D l \Delta P} \\
& 1 \mathrm{GPU}=1 \times 1^{-6} \frac{\mathrm{cm}^{3}(\mathrm{STP})}{\mathrm{cm}^{2} \mathrm{~s} \mathrm{~cm} \mathrm{Hg}}
\end{aligned}
$$

Selectivity, $\alpha$ :

$$
\alpha_{A / B}=\frac{P_{A}}{P_{B}}=\frac{(P / l)_{A}}{(P / l)_{B}}
$$

where $P / l$ is the permeance of the hollow fiber $\left(\mathrm{cm}^{3}\right.$ (STP) $/ \mathrm{cm}^{2}$.s.cmHg), $Q_{i}$ is the volumetric flow rate of gas $i$ at standard temperature and pressure $\left(\mathrm{cm}^{3}(\mathrm{STP}) / \mathrm{s}\right), D p$ is the pressure difference between the feed side and the permeation side of the membrane $(\mathrm{cmHg}), A$ is the membrane surface area $\left(\mathrm{cm}^{2}\right), n$ is the number of fibers in the module, $D$ is an outer diameter of hollow fiber $(\mathrm{cm})$ and $l$ is an effective length of hollow fiber $(\mathrm{cm})$.

\subsection{RESULTS AND DISCUSSION}

\subsection{Morphological Structure}

Figure 1 depicts the morphological structure of the resultant CHFMs prepared under different stabilization temperatures. It can be observed that the two dense layers, both outer and inner layer with porous sub-layer in between was obtained for all the resultant carbon membranes. This structure was generated during the dry/wet spinning process as the result of the phase inversion between polymer solution and coagulation liquid. 

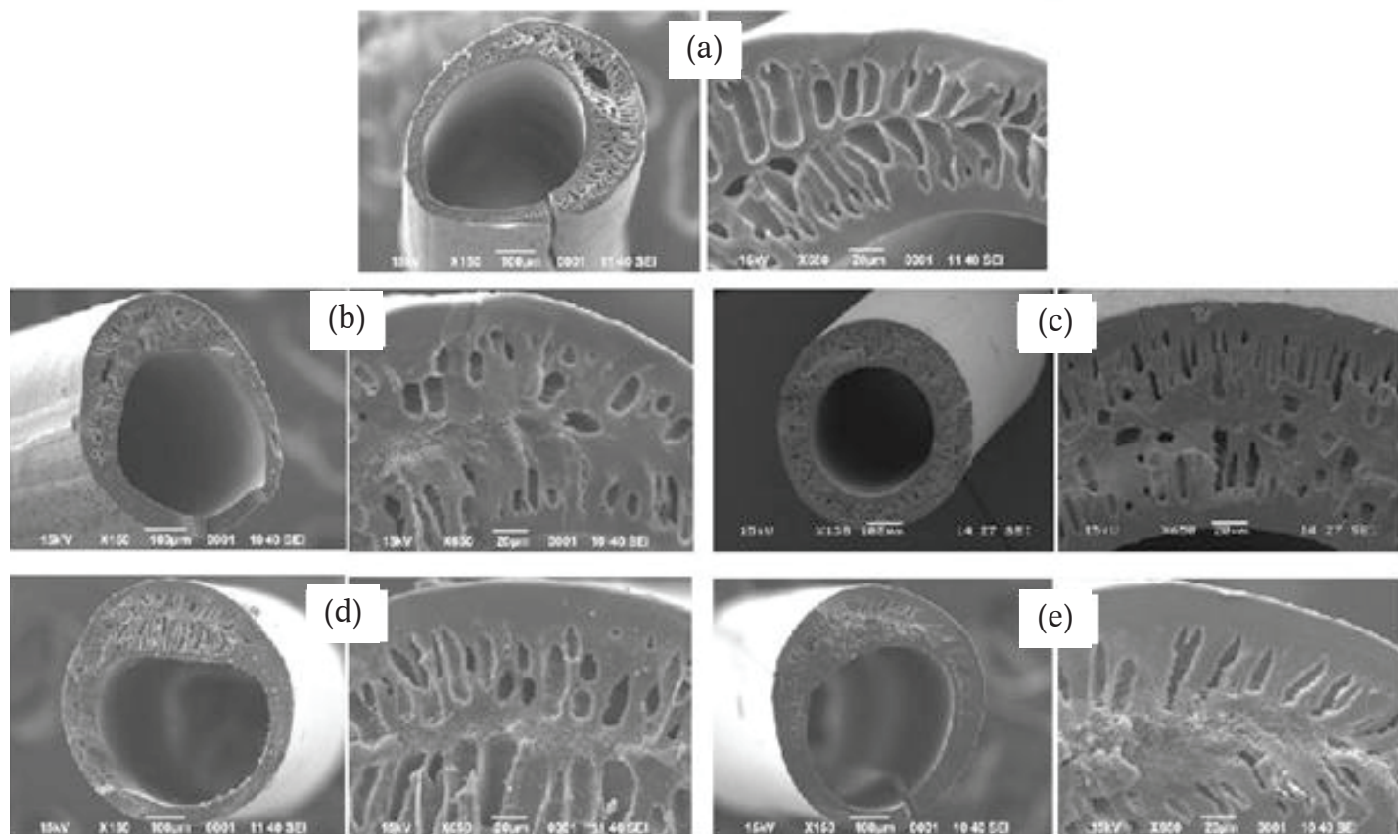

Figure 1 SEM microphotographs of the PEI/PVP-based CHFMs prepared at different stabilization temperatures; (a) $200^{\circ} \mathrm{C}$, (b) $250^{\circ} \mathrm{C}$, (c) $300^{\circ} \mathrm{C}$, (d) $350^{\circ} \mathrm{C}$, and (e) $400^{\circ} \mathrm{C}$

This reveals that the structure of the membranes is preserved after heat treatment process and any arrangement of the structure on precursor membrane does not occur during stabilization and carbonization steps. Moreover, there is no cross section deformation and irregularities were observed for the carbon membranes prepared under stabilization temperature of $300^{\circ} \mathrm{C}$. It is shows that the precursor was fully stabilized and the oxidation reactions were more effective at $300^{\circ} \mathrm{C}$ under air flow. The similar finding has been reported by Linkov et al. [14] Sedigh et al. [15] Coutinho et al. [5] Rao et al. [16] and $\mathrm{Xu}$ et al. [17].

\subsection{Gas Permeation Properties}

The influence of stabilization temperature on the gas permeation properties of the resultant CHFM is summarized in Table 1 . The gas permeance

Table 1 Gas separation properties of the resultant CHFMs prepared at different stabilization temperatures (Error analysis is about $\pm 10 \%$ )

\begin{tabular}{cccccc}
\hline $\begin{array}{c}\text { Stabilization } \\
\text { Temperature }\left({ }^{\circ} \mathbf{C}\right)\end{array}$ & \multicolumn{3}{c}{ Permeance } & \multicolumn{2}{c}{ Selectivity } \\
\cline { 2 - 6 } & $\mathbf{N}_{\mathbf{2}}$ & $\mathbf{C H}_{\mathbf{4}}$ & $\mathbf{C O}_{\mathbf{2}}$ & $\mathbf{C O}_{\mathbf{2}} / \mathbf{C H}_{\mathbf{4}}$ & $\mathbf{C O}_{\mathbf{2}} / \mathbf{N}_{\mathbf{2}}$ \\
\hline PEI-based CHFM & 1.34 & 1.02 & 13.32 & 13.06 & 9.94 \\
200 & 0.21 & 0.20 & 2.20 & 11.50 & 10.48 \\
250 & 0.08 & 0.05 & 1.70 & 34.00 & 21.25 \\
300 & 0.04 & 0.03 & 1.66 & 55.33 & 41.50 \\
350 & 0.04 & 0.02 & 1.03 & 51.50 & 25.75 \\
400 & 0.15 & 0.12 & 1.85 & 15.42 & 12.33 \\
\hline
\end{tabular}

* Tested at 7 bar, $25^{\circ} \mathrm{C}$ 
of the CHFMs remarkably decreased as the stabilization temperature increased from 200 to $350^{\circ} \mathrm{C}$. It is due to the deterioration in original backbone of the polymer and formed much more activated points composed of oxygen-containing groups as the stabilization temperature increased, which will affect the developed pore system in the resultant CHFM. During subsequent carbonization process, the pore structure of the resultant CHFMs shrinks and even collapse to form an impermeable bulk carbon structure by the rapid evolution of those activated points. However, the gas permeance of all the gases increased when the stabilization temperature reached $400^{\circ} \mathrm{C}$. It is indicated that an excessive stabilization reaction has occurred and leads to the development of defects and an enlargement of pore size [18]. The pore size of the resultant CHFM probably was too large for an effective separation. It is established that small changes in the pore size of the carbon structure can have a considerable impact on gas permeation properties of the resultant CHFMs since the pore network created in this membrane are similar in size to the gas penetrant [19].

Based on gas permeation data, the gas permeance of the tested gases were in the order $\mathrm{CO}_{2}>\mathrm{N}_{2}>\mathrm{CH}_{4}$, which consistent with the order of the kinetic diameters of the gas molecules $\left(\mathrm{CO}_{2}(3.3 \AA)>\mathrm{N}_{2}(3.64 \AA)>\mathrm{CH}_{4}(3.8 \AA)\right)$. This indicates that the gas permeation through these carbon membranes obeys molecular sieving mechanism. This result is in agreements with the work reported by previous researchers [16, 20]. The selectivity of $\mathrm{CO}_{2} / \mathrm{CH}_{4}$ and $\mathrm{CO}_{2} / \mathrm{N}_{2}$ as high as 55.33 and 41.50, have been achieved for CHFMs prepared at stabilization temperature of $300^{\circ} \mathrm{C}$. The $\mathrm{CHFMs}$ prepared at stabilization temperature of $350^{\circ} \mathrm{C}$ also exhibited a promising gas separation performance for $\mathrm{CO}_{2} / \mathrm{CH}_{4}$ and $\mathrm{CO}_{2} / \mathrm{N}_{2}$ but exhibited the lowest gas permeance for all the tested gases compared to those CHFMs prepared at stabilization temperature of 200, 250, 300 , and $400^{\circ} \mathrm{C}$.

Such selectivity that obtained was still in the range of current attractive result for $\mathrm{CO}_{2} /$ $\mathrm{CH}_{4}$ and $\mathrm{CO}_{2} / \mathrm{N}_{2}$ separation. This was probably owing to the formation of micropores, which connecting to each others, and mesopores, which do not penetrate through the total thickness of the CHFMs, as demonstrated in the preparation of carbon membrane derived from BPDA-pp'ODA polyimide [21]. Therefore, by considering the morphological structure, dissolution test, mechanical stability, and gas separation performance, the stabilization temperature at $300^{\circ} \mathrm{C}$ under air atmosphere is the best conditions for PEI/PVP-based CHFMs preparation.

\subsection{CONCLUSIONS}

This study represents the CHFMs derived from PEI/PVP prepared at different stabilization conditions. SEM microphotographs reveal that the structure of the CHFMs is preserved after heat treatment process and any arrangement of the structure on precursor membrane does not occur during stabilization and carbonization steps. It is showed that there is no cross section deformation and irregularities were observed for the CHFMs prepared under stabilization temperature of $300^{\circ} \mathrm{C}$. This study elucidate that the gas permeance of the CHFMs remarkably decreased as the stabilization temperature increased from 200 to $350^{\circ} \mathrm{C}$ and increased when the stabilization temperature proceed to $400^{\circ} \mathrm{C}$. In overall, the stabilization step at $300^{\circ} \mathrm{C}$ under air atmosphere show the best condition in the preparation of the PEI/PVP-based CHFMs for gas separation.

\section{ACKNOWLEDGEMENTS}

One of the authors, Salleh WNW, gratefully acknowledged the financial support under National Science Fellowship (NSF) from the Ministry of Science, Technology and Environment of Malaysia.

\section{REFERENCES}

[1] P. Pandey, R. S. Chauhan. 2001. Membrane for gas separation. Prog. Polym. Sci. 26: 853-893. 
[2] V. C. Geiszler. 1997. Polyimde precursor for carbon molecular sieve membranes. The University of Texas. PhD Thesis.

[3] P. S. Tin, T. S. Chung, A. J. Hill. 2004. Advanced fabrication of carbon molecular sieve membranes by nonsolvent pretreatment of precursor polymers. Ind. Eng. Chem. Res. 43: 6476-6483.

[4] C. J. Anderson, S. J. Pas, G. Arora, S. E. Kentish, A. J. Hill, S. I. Sandler, G. W. Stevens. 2008. Effect of pyrolysis temperature and operating temperature on the performance of nanoporous carbon membranes. J. Membr. Sci. 322: 19-27.

[5] E. B. Coutinho, V. M. M. Salim, C. P. Borges. 2003. Preparation of carbon hollow fiber membranes by pyrolysis of polyetherimide. Carbon 41: 1707-1714.

[6] H. J. Lee, H. Suda, K. Haraya, S. H. Moon. 2007. Gas permeation properties of carbon molecular sieving membranes derived from the polymer blend of polyphenylene oxide (PPO)/polyvinylpyrrolidone (PVP). J. Membr. Sci. 296: 139-146.

[7] T. Wang, B. Zhang, J. Qiu, Y. Wu, S. Zhang, Y. Cao. 2009. Effects of sulfone/ketone in poly(phthalazinone ether sulfone ketone) on the gas permeation of their derived carbon membranes. J. Membr Sci. 330: 319-325.

[8] A. Bos, I. G. M. Punt, M. Wessling, H. Strathmann. 1998 Plasticization-resistant glassy polyimide membranes for $\mathrm{CO}_{2} / \mathrm{CO}_{4}$ separations. Sep. Purif. Tech. 14: 27-39.

[9] J. Drbohlav, W. T. K. Stevenson. 1995. The oxidative stabilization and carbonization of a synthetic mesophase pitch, Part I: The oxidative stabilization process. Carbon. 33 (5): 693-711.

[10] W. N. W. Salleh, A. F. Ismail. 2011. Carbon hollow fiber membranes derived from PEI/ PVP for gas separation. Sep. Purif. Tech. 80: 541-548.

[11] W.N.W. Salleh, A.F. Ismail. 2012. Effects of carbonization heating rate on $\mathrm{CO} 2$ separation of derived carbon membranes. Sep. Purif. Tech. 88: 174-183.

[12] W. N. W. Salleh, A. F. Ismail, Fabrication and characterization of PEI/PVP-based carbon hollow fiber membranes for $\mathrm{CO}_{2} / \mathrm{CH}_{4}$ and $\mathrm{CO}_{2} / \mathrm{N}_{2}$ separation. AIChE J. Article in press.

[13] W.N.W. Salleh, A.F. Ismail. Effect of stabilization temperature on gas permeation properties of carbon hollow fiber membrane, J. Appl. Polym. Sci. Article in press.

[14] V. M. Linkov, R. D. Sanderson, E. P. Jacobs. 1994. Carbon Membranes from Precursors Containing Low-Carbon Residual Polymers. Polym. Int. 35: 239-242.

[15] M. G. Sedigh, L. Xu, T. T. Tsotsis, M. Sahimi. 1999. Transport and morphological characteristics of polyetherimide-based carbon molecular sieve membranes. Ind. Eng. Chem. Res. 38: 3367-3380.

[16] P. S. Rao, M. Y. Wey, H. H. Tseng, I. A. Kumar, T. H. Weng. 2008. A comparison of carbon/nanotube molecular sieve membranes with polymer blend carbon molecular sieve membranes for the gas permeation application. Microp. Mesop. Mat. 113: 499-510.

[17] S. Xu, J. Li, G. Qiao, H. Wang, T. Lu. 2009. Pore structure control of mesoporous carbon monoliths derived from mixtures of phenolic resin and ethylene glycol. Carbon. 47: 2103-2111.

[18] A. B. Fuertes, Effect of air oxidation on gas separation properties of adsorptionselective carbon membranes. 2001. Carbon. 39: 697-706.

[19] P. J. Williams. 2006. Analysis of factors influencing the performance of $\mathrm{cms}$ membranes for gas separation. Georgia Institute Of Technology. PhD Thesis.

[20] B. Zhang, T. Wang, Y. Wu, Q. Liu, S. Liu, S. Zhang, J. Qiu. 2008. Preparation and gas permeation of composite carbon membranes from poly (phthalazinone ether sulfone ketone). Sep. Purif. Tech. 60: 259263.

[21] K. Kusakabe, M. Yamamoto, S. Morooka. 1998. Gas permeation and micropore structure of carbon molecular sieving membranes modified by oxidation. $J$. Membr. Sci. 149: 59-67. 